\title{
EDITORAÇÃO DA REVISTA “PSICOLOGIA ESCOLAR E EDUCACIONAL”
}

\author{
Marilda Gonçalves Dias Facciㄹ; Silvia Maria Cintra Silva²; Marilene Proença Rebello Souza ${ }^{3}$
}

\section{Como citar:}

FACCI, M. G. D.; SILVA, S. M. C.; SOUZA, M. P. R. Editoração da revista "psicologia escolar e educacional". In: ABEC MEETING, 1, 2017, Curitiba. Anais... Curitiba: Associação Brasileira de Editores Científicos, 2017. p. $21-25$

http://dx.doi.org/10.21452/abecmeeting.2017.004

Resumo: O objetivo deste pôster é apresentar informações sobre a revista Psicologia Escolar e Educacional. Essa é um veículo de divulgação e debate da produção científica na área específica, desde 1996, e está vinculada à Associação Brasileira de Psicologia Escolar e Educacional (ABRAPEE). Seu objetivo é constituir um espaço para a apresentação de pesquisas atuais no campo da Psicologia Escolar e Educacional e servir como um veículo de divulgação do conhecimento produzido na área, bem como de informação atualizada a profissionais psicólogos e de áreas correlatas. Trabalhos originais que relatam estudos em áreas relacionadas à Psicologia Escolar e Educacional serão considerados para publicação, incluindo processos básicos, experimentais, aplicados, naturalísticos, etnográficos, históricos, artigos teóricos, análises de políticas e sínteses sistemáticas de pesquisas, entre outros. Também, revisões críticas de livros, instrumentos diagnósticos e softwares. Com vistas a estabelecer um intercâmbio entre seus pares e pessoas interessadas na Psicologia Escolar e Educacional, conta com uma revisão às cegas por pares e é publicada semestralmente. São publicados textos em português, espanhol e inglês. Qualis A2

Palavras-chave: Psicologia escolar e educacional. Educaçao. Editoração.

Abstract: The purpose of this poster is to present information about the journal Psicologia Escolar e Educacional. This is a journal associated to the Brazilian Association of Educational and School Psychology (Associação Brasileira de Psicologia Escolar e Educacional - ABRAPEE), for the communication and debate of the scientific production in its area of specificity, since 1996. Its objective is to provide a medium for the presentation of the latest research in the field of Educational and School Psychology, for spreading knowledge, which is being produced in the area, as well as updated information to psychologists and other professionals in correlated areas. Original papers, which report studies related to Educational and School Psychology may be considered for publication, including, among others: basic processes, experimental or applied, naturalistic, ethnographic, historic, theoretical papers, analyses of policies, and systematic syntheses of research, and also critical reviews of books, diagnostic instruments and software. As a means of establishing an interchange among peers, as well as people who are interested in Educational and School Psychology, it employs a double blind review by peers and it is published semiannually. Texts in Portuguese, Spanish and English are published. Qualis A2.

Keywords: School and educational psychology. Education. Publishing.

\section{INTRODUÇAO}

\section{A Revista Psicologia Escolar e Educacional é editada e mantida pela Associação} Brasileira de Psicologia Escolar e Educacional - ABRAPEE, entidade sem fins lucrativos. A Revista passou a ser indexada na base de dados SciELO a partir de Agosto de 2010 e foi classificada pela Comissão de Avaliação de Periódicos CAPES/ANPEPP da área de Psicologia, em 2016, obtendo a classificação A2 no Qualis Periódicos CAPES. Possui abrangência nacional e internacional quanto a autores e corpo editorial em todos os fascículos e adota política editorial estrita de revisão por pares às cegas. 
A Revista tem $100 \%$ de artigos científicos e/ou técnico-científicos publicados e gerados a partir de pesquisas originais, não divulgadas em outras revistas. Até 2014 tinha uma periodicidade de dois fascículos ao ano e circula de forma regular desde 1996, mantendo essa periodicidade até a atualidade. A partir de 2014 passou a ser quadrimestral, ou seja, publica três fascículos por ano, apenas na versão eletrônica. Em relação a outros periódicos da mesma área representa a opção majoritária de publicações por autores brasileiros.

Possui número internacional normatizado para publicações seriadas - ISSN (obtido junto ao Instituto Brasileiro de Informação em C\&T-IBICT) e ISSN 2175-3539 (versão eletrônica).

Os conteúdos dos artigos publicados não reflete a posição, opinião ou filosofia da Associação Brasileira de Psicologia Escolar e Educacional. Tem como objetivo constituir um espaço para a apresentação de pesquisas atuais no campo da Psicologia Escolar e Educacional e servir como um veículo de divulgação do conhecimento produzido na área, bem como de informação atualizada a profissionais psicólogos e de áreas correlatas.

Neste sentido, são considerados para publicação trabalhos originais que relatam estudos e/ou pesquisas em áreas relacionadas à Psicologia Escolar e Educacional, incluindo processos básicos, experimentais, aplicados, naturalísticos, etnográficos, históricos, artigos teóricos, análises e sínteses sistemáticas de pesquisas, além de revisões críticas de livros, instrumentos diagnósticos e softwares. São publicados textos em português, espanhol, inglês e francês. Trata-se do único periódico na área de Psicologia Escolar e Educacional no Brasil, que tem por missão publicar manuscritos referentes à atuação, formação e história da Psicologia no campo da educação, textos de reflexão crítica sobre a produção acadêmicocientífica e relatos de pesquisas nas áreas de Psicologia Escolar e Educacional, bem como na sua interface com a Educação.

A revista Psicologia Escolar e Educacional conta com uma revisão às cegas, garantindo o anonimato tanto dos autores dos originais quanto dos pareceristas.

\section{CORPO EDITORIAL}

O período possui três editoras gerais e quatro editoras de seção, quatro membros da comissão editorial, todos professores e pesquisadores de diversas universidades do Brasil. O conselho editorial é composto por pesquisadores brasileiros e de outros países, totalizando 43 estudiosos. Conta, ainda com uma equipe de apoio constituída por alunas de pós-graduação.

\section{INFORMAÇÃO SOBRE O FLUXO DOS ARTIGOS}


Em 2014 foram recebidos 107 manuscritos; em 2015 computaram 144 artigos e em 2016 o total de trabalhos recebidos chegou a 178. Até setembro de 2017 recebeu 145 manuscritos para serem avaliados. Observa-se, neste ponto um crescimento no interesse de pesquisadores brasileiros e estrangeiros em publicar as pesquisas na revista Psicologia Escolar e Educacional.

O prazo médio de tramitação do manuscrito - do recebimento até o parecer final é de 6 (seis) meses. No entanto, a publicação tem sido mais demorada, considerando o elevado número de trabalhos aprovados. Cerca de $50 \%$ dos artigos são reprovados, sendo que uma parte destes são rejeitados porque não se enquadram no escopo da revista.

\section{INDEXADORES}

- PePsic (metodologia Scielo) - Nacional/ Internacional

- IndexPsi - Nacional

- LILACS - Latino-américa e Caribe

- $\quad$ ReBAP - Nacional

- CLASE - Latino-américa

- DOAJ (Directory of Open Access Journals)

- $\quad$ PSICODOC

- REDALYC (Red de Revistas Científicas de America Latina y El Caribe, España y Portugal)

- SciELO - Scientific Electronic Library Online

- SCOPUS / Elsevier

\section{ALGUMAS CONSIDERAÇOES}

A meta da equipe editorial é manter a qualidade do processo editorial de forma a garantir a divulgação do que há de mais reconhecido academicamente na área de Psicologia Escolar e Educacional, nacional e internacionalmente. Pretente ainda, ampliar a visibilidade nacional e internacional da Revista por intermédio da inserção da Revista em outras Base de Dados, priorizando para o momento obter a indexação na PsycINFO(American PsychologicalAssociation), Sociological Abstracts (Cambridge Scientific Abstracts), Social Services Abstracts, Linguistics\&LanguageBehavior Abstracts, LATINDEX.

Em termos gerais, na relação entre Psicologia e Educação, a concepção de Psicologia Escolar e Educacional, defendida pelas autoras deste trabalho, é aquela que compreende o homem como multideterminado, como "síntese das relações sociais", que desenvolve suas 
potencialidades a partir da apropriação dos conhecimentos científicos, conforme propõe Vigotski (2000). Neste aspecto, ocorre uma grande valorização do processo de escolarização para o desenvolvimento do psiquismo. Fica claro, também, a partir de Vigotski (2001) que cabe a psicologia dar fundamentos para a educação no entendimento do desenvolvimento do psiquismo e como ocorre o processo ensino-aprendizagem.

Compreendemos que a veiculação de um periódico científico é um espaço político, uma vez que trata do cotidiano da escola e também do que ocorre no cenário brasileiro e de outros países, procurando compreender as contradições de que estão presentes na sociedade, que permeiam as políticas educacionais que reverberam no fazer pedagógico. No vários números editados pode-se trazer elementos para instrumentalizar profissionais $\mathrm{e}$ pesquisadores em busca da emancipação humana, no sentido de garantir, no espaço educativo, que todos da comunidade escolar (pais, professores, alunos, funcionários) possam se apropriar da riqueza do legado cultural produzido pela humanidade. Compreendemos que a circulação das ideias, presentes nos vários manuscritos, podem contribuir para a efetiva atuação de educadores na busca de soluções entre o que propõe e o que é efetivado nas políticas públicas educacionais no enfrentamento do fracasso escolar e outras problemática que se tem assistido nos tempos atuais (Souza, 2006). A luta é contra o esvaziamento da escola e do trabalho do professor, conforme defende Facci (2004), e a busca por trabalhos coletivos que possam transformar a consciência daqueles que passam pelos bancos escolares.

Finalizando, entendemos que pensar a relação entre psicologia e educação é um desafio que é construído historicamente e do qual os autores dos artigos publicados muito tem contribuído.

\section{REFERENCIAS}

FACCI, Marilda Gonçalves Dias. Valorização ou esvaziamento do trabalho do professor? Um estudo crítico-comparativo da Teoria do Professor Reflexivo, do Construtivismo e da Psicologia Vigotskiana. Campinas: Autores Associados, 2004.

SOUZA, Marilene Proença Rebello. Políticas públicas e educação: problemas e possibilidades. In: VIÉGAS, Lygia de Souza; ANGELUCCI, Carla Biancha. (orgs.). Políticas Públicas em Educação - Uma análise crítica a partir da Psicologia. São Paulo: Casa do Psicólogo, p. 229-243, 2006.

VIGOTSKI, Liev Semióniovich. S. A construção do pensamento e da linguagem. São Paulo: Martins Fontes, 2000.

VIGOTSKI, Liev Semionovich. Psicologia pedagógica: un curso breve. Buenos Aires: AIQUE, 2001. 